\title{
Interstitial cells of Cajal in enteric neurotransmission
}

\author{
S M Ward
}

Specialised cells known as interstitial cells of Cajal (ICCs), distributed in specific locations within the tunica muscularis of the gastrointestinal tract, serve as electrical pacemakers and mediators of enteric neurotransmission. Until recently, evidence to support a functional role of these cells has been, for the most part, indirect.

The role of ICCs in pacemaking or neurotransmission has been tested by experiments in which: (i) ICCs were removed by dissection $^{1-3}$; (ii) ICCs were lesioned by cytotoxic chemicals thought to have specificity for these cells ${ }^{4-6}$; (iii) the excitability properties and responses to drugs were directly studied in isolated $\mathrm{ICCs}^{7}$; (iv) morphological studies revealed close relationships between ICCs and varicose nerve fibres (see fig 1); and (v) ICCs responded to neurotransmitters when studied using immunohistochemical techniques. ${ }^{9} 10$
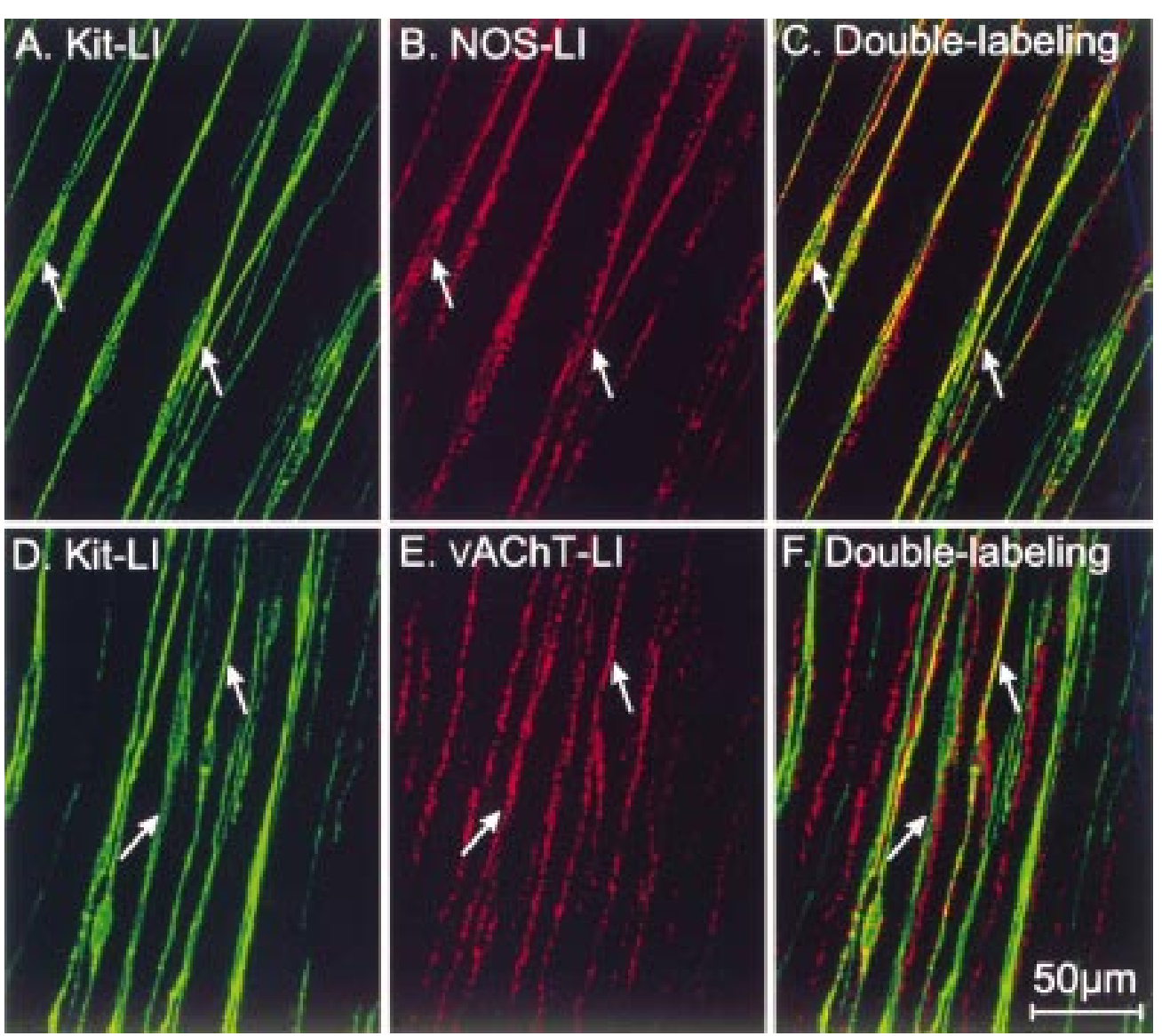

Figure 1 Confocal micrographs of whole mount preparations showing double labelling with the receptor tyrosine kinase, Kit (FITC; A) and nitric oxide synthase (NOS; Texas Red; B) or vesicular acetylcholine transporter (vAChT) antibodies in the circular muscle layer of the murine gastric fundus. (A) Spindle shaped interstitial cells of circular and longitudinal muscle (IC-IM) immunopositive for Kit (green; arrows) within the circular muscle layer. (B) NOS-LI in enteric inhibitory nerves (arrows); IC-IM also appeared immunoreactive for NOS $(C) .(D, E)$ Double labelling of Kit (D) and $v A C h T(E)$. Double labelling of Kit-LI and vAChT-LI is shown in $(F)$. Courtesy of Wang et al. ${ }^{30}$
Recent findings have shown that several lasses of ICCs of the mouse and other species vation of Kit by its ligand, stem cell factor, or of ICCs because blockade of Kit with neutralsteel $^{15}$ impair the development of ICCs at the level of the myenteric plexus in the small inteswith abnormal electrical activity in this region of the gut, including loss of electrical slow

Abbreviations used in this paper: ICC, interstitial cells of Cajal; NOS, nitric oxide synthase; vAChT, vesicular acetylcholine transporter; IC-MY, interstitial cells of the myenteric plexus; IC-IM, interstitial cells of
circular and longitudinal muscle; IC-DMP, interstitial cells of deep muscular plexus; cGMP, cyclic guanosine monophosphate.

Department of Medicine, Reno Nevada 89557, USA S M Ward 


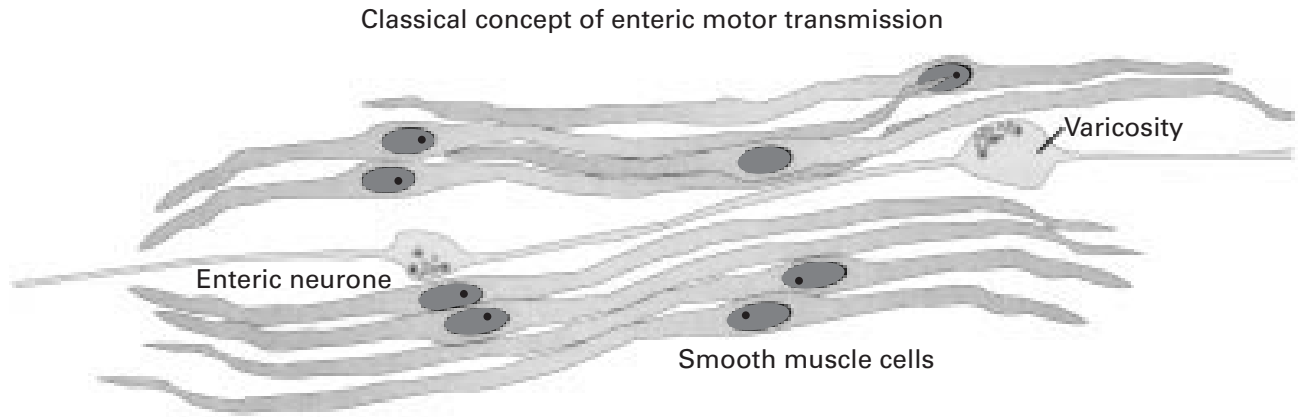

Figure 2 Model for current concept of enteric motor neurotransmission. Transmitter is released from nerve varicosities and diffuses through a loosely defined postjunctional volume with subsequent binding and activation of receptors expressed on neighbouring smooth muscle cells. Excitatory or inhibitory responses are dependent on the type and number of receptors activated.

a second population of ICCs located within the circular and longitudinal muscle layers (ICIM) of the stomach as well as in the lower oesophageal, pyloric, and internal anal sphincters also fail to develop and neurotransmission is compromised in these tissues, ${ }^{16}{ }^{17}$ providing functional evidence for the intercalation theory proposed by Cajal in $1911 .^{18}$

Although all of these studies support the proposed functional roles for ICC, much has yet to be learned about basic mechanisms of rhythmicity and transduction of neural inputs, the specific contributions of ICCs and smooth muscle cells to these behaviours, and the factors that regulate the development of ICCs and the formation of ICC/smooth muscle networks and enteric neurone/ICC/smooth muscle motor units in the various organs of the gastrointestinal tract. A powerful means of investigating the physiological role of ICCs is to manipulate the development of these cells and the formation of ICC networks. ${ }^{19}$ In order to design such studies properly, it is necessary to understand the time course of and factors that regulate ICC development. Developmental studies, however, have been hampered by lack of specific cellular labels for ICCs. Rigorous identification of these cells has required ultrastructural studies. Faussone-Pellegrini $(1984)^{20}$ studied the development of ICCs using transmission electron microscopy, but the conclusions that ICCs developed well after birth are inconsistent with the observation that electrical rhythmicity can be measured at or before birth. ${ }^{21}{ }^{22}$ Use of ultrastructural criteria may not be the best means of following the development of ICCs because the features commonly associated with the mature phenotype may not develop as early as cellular function. Recent findings that ICCs express Kit protein makes it possible, using specific antibodies and immunohistochemistry, to follow the development of these cells back into the embryonic period and to investigate the relationship between the development of ICCs and the initiation of electrical rhythmicity and/or development of postjunctional neural responses. Kit expression in the small bowel begins midway through gestation. Cells within the tunica muscularis that express Kit develop before birth within the myenteric plexus region and form characteristic ICC networks (ICMY). After birth, ICCs continue to develop within the region of the deep muscular plexus of the small intestine, forming networks of IC-DMP. ${ }^{21}$ Blocking of the ICC networks in newborn animals using neutralising antibodies disrupts IC-MY and electrical rhythmicity and reduces responses to electrical field stimulation in the murine jejunum, suggesting that Kit is critical not only for the development but also for the maintenance of ICCs, electrical rhythmicity, and neural responses. ${ }^{22}$

Physiological and morphological studies have also shown that inhibitory innervation of gastrointestinal muscles is concentrated in regions where ICCs are located,,$^{23-25}$ and isolated ICCs have been shown to be responsive to a variety of enteric transmitters, including nitric oxide (NO) and substance $\mathrm{P}^{26}{ }^{27}$ Using antibodies raised against formaldehyde fixed cyclic guanosine monophosphate (cGMP), ${ }^{28}$ ICCs have been evaluated specifically as targets for NO by monitoring changes in cellular levels of cGMP in response to NO donors and stimulation of enteric neurones. ${ }^{9} 10$ The role of ICCs in neurotransmission has also been supported in studies showing that loss of a specific population of ICCs in the murine stomach results in loss of $\mathrm{NO}$ dependent neurotransmission. ${ }^{1617}$ Although numerous ultrastructural studies with transmission electron microscopy have shown close apposition between enteric neurones and ICCs, the extent and specifics of this innervation have been documented only recently. Antibodies directed against the intermediate filament marker, vimentin, and the receptor tyrosine kinase, Kit, to label ICCs I $^{12-162129}$ and antibodies directed against substance $\mathrm{P}$, vesicular acetylcholine transporter (vAChT) and NO synthase (NOS) have been used recently to label excitatory and inhibitory motor neurones, respectively. Neurones with NOS, vAChT, and substance P-like immunoreactivities are closely associated with the cell bodies of interstitial cells and ramify along their processes for distances greater than $300 \mu \mathrm{m}$ (fig 1). With transmission electron microscopy, we noted close relationships between interstitial cells and NOS, vAChT, and substance P-like immunoreactive axonal varicosities. Varicosites of NOS, vAChT, and substance P-like neurones were found as close as 20 and $25 \mathrm{~nm}$ from interstitial cells, respectively. Using immunocytochemistry, we have also recently demonstrated the existence of 


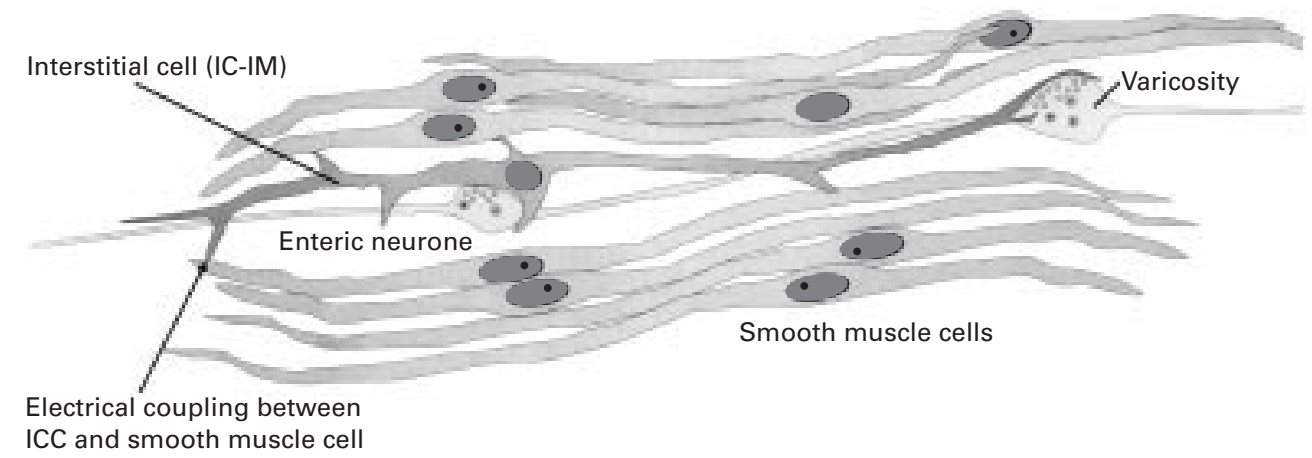

Figure 3 Alternative model consistent with recent morphological and physiological data is a refinement of the concept first proposed by Cajal ${ }^{18}$ and later by Daniel and Posey-Daniel. ${ }^{32}$ Neurotransmitter released from enteric motor neurones binds primarily to receptors expressed by interstitial cells of Cajal (ICCs). Activation (depolarisation or hyperpolarisation) of neighbouring smooth muscle cells occurs by conduction of excitatory or inhibitory junction potentials via gap junctions between ICCs and smooth muscle cells. Thus terminals of enteric motorneurones, interstitial cells of circular and longitudinal muscle (IC-IM), and smooth muscle cells form functional units that release transmitter and mediate and transduce neural inputs into mechanical responses. IC-IM appear to be a critical component in these functional units. The physically close association between varicose nerve terminals and ICCs suggests specialised neuro-ICC junctions may be the primary sites of innervation.

specialised synapse-like contacts between enteric neurones and ICCs within the circular and longitudinal muscle layers in the murine gastric fundus and ICCs within the deep muscular plexus (IC-DMP) in the guinea pig small intestine. Close structural relationships (approximately $25 \mathrm{~nm}$ ) were also occasionally observed between either NOS, vAChT, and substance P-like immunoreactive varicosities and smooth muscle cells in the circular layer of the murine fundus and the outer circular muscle layer of the guinea pig small intestine. ${ }^{30}$ These data suggest that interstitial cells in the gastric fundus and deep muscle plexus of the small intestine are heavily innervated by excitatory and inhibitory enteric motor neurones. In $W / W^{V}$ mutant animals, the absence of IC-IM in the murine fundus led not only to reduced NO dependent postjunctional responses but also resulted in loss of cholinergic excitatory responses. Thus the existence of synaptic-like specialisations and loss of inhibitory and excitatory neural responses suggest that ICCs may provide an important, but probably not exclusive, pathway for nervemuscle communication in the gastrointestinal tract.

In conclusion, the current concept of classical neuromuscular transmission in the gastrointestinal tract, which is thought to occur via release and diffusion of the transmitter through a loosely defined postjunctional volume with subsequent binding and activation of receptors expressed by neighbouring smooth muscle cells, ${ }^{31}$ should be reconsidered (see fig 2 ).

Recent morphological and physiological studies suggest that this concept is incomplete and that an alternative model first proposed by Cajal $(1911)^{18}$ and later by Daniel and Posey-Daniel $(1984)^{32}$ is more consistent with recent findings in the murine stomach. That is, transmitter released from enteric motor neurones binds primarily to receptors expressed by ICCs. Activation (depolarisation or hyperpolarisation) of neighbouring smooth muscle cells occurs by conduction of excitatory or inhibitory junction potentials via gap junctions between ICCs and smooth muscle cells (see fig 3). Thus terminals of enteric motorneurones, IC-IM, and smooth muscle cells form functional units that release transmitter and mediate and transduce neural inputs into mechanical responses.

1 Suzuki N, Prosser CL, Dahms V. Boundary cells between longitudinal and circular layers: essential for electrical slow waves in cat intestine. Am f Physiol 1986;250:G287-94.

2 Hara Y, Kubota M, Szurszewski JH. Electrophysiology of smooth muscle of the small intestine of some mammals. $\mathcal{F}$

3 Smith TK, Reed JB, Sanders KM. Origin and propagation of electrical slow waves in circular muscle of canine proximal colon. Am f Physiol 1987;252:C215-24.

4 Thuneberg L, Johanson V, Rumenssen JJ, et al. Interstitial cells of Cajal (ICC): selective uptake of methylene blue nhibits slow wave activity. In: Roman C, ed. Gastrointestinal motility. Lancaster: MTP, 1983:495-502.

5 Ward SM, Burke EP, Sanders KM. Use of rhodamine 123 to label and lesion interstitial cells of Cajal in canine colonic circular muscle. Anat Embryol 1990;182:215-24.

6 Liu LWC, Thuneberg L, Huizinga JD. Selective lesioning of interstitial cells of Cajal by methylene blue and light leads

7 Langton P, Ward SM, Carl A, et al. Spontaneous electrical activity of interstitial cells of Cajal isolated from canine

proximal colon. Proc Natl Acad Sci USA 1989;86:7280-4. Lee HK, Sanders KM. Comparison of ionic currents from
interstitial cell and smooth muscle cells of canine colon. $\mathcal{F}$ interstitial cell and smooth

9 Young HM, McConalogue K, Furness JB, et al. Nitric oxide targets in the guinea-pig intestine identified by induction of cyclic GMP immunoreactivity. Neuroscience 1993;55:58396

10 Shuttleworth CW, Xue C, Ward SM, et al. Immunohistochemical localization of 3',5'-cyclic guanosine monophosphate in the canine proximal colon: Responses to nitric oxide and electrical stimulation of enteric inhibitory neurones. Neuroscience 1993;56:513-22.

11 Maeda H, Yamagata A, Nishikawa S, et al. Requirement of c-kit for development of intestinal pacemaker system. Development 1992;116:369-75.

12 Torihashi S, Ward SM, Nishikawa S-I, et al. c-kit-dependent development of interstitial cells and electrical activity in the
murine gastrointestinal tract. Cell Tissue Res 1995;280:97111 .

13 Ward SM, Burns AJ, Torihashi S, et al. Mutation of the proto-oncogene c-kit blocks development of interstitial cells and electrical rhythmicity in murine intestine. F Physiol 1994;480:91-7.

14 Huizinga JD, Thuneberg L, Kluppel M, et al. W/kit gene required for intestinal pacemaker activity. Nature 1995;373: $347-9$.

15 Ward SM, Burns AJ, Torihashi S, et al. Impaired development of interstitial cells and intestinal electrical rhythmicity

16 Burns AJ, Lomax AEJ, Torihashi S, et al. Interstitial cells of Cajal mediate inhibitory neurotransmission in the stomach. Proc Natl Acad Sci USA 1996;93:12008-13.

17 Ward SM, Morris G, Reese L, et al. Interstitial cells of Cajal mediate inhibitory neurotransmission in the lower esophageal and pyloric sphincters. Gastroenterology 1998;115:1- 
18 Cajal SR. Histologie du systeme nerveaux de l'homme et des vertebres, vol. 2. Paris: Maloine, 1911:891-942.

19 Sanders KM. A case for interstitial cells of pacemakers and mediators of neurotransmission in the gastrointestinal tract. Gastroenterology 1996;111:492-515.

20 Faussone-Pellegrini MS. Morphogenesis of the special circular muscle layer and of the interstitial cells of Cajal related to the plexus muscularis profundus of mouse intestinal muscle coat. An E.M. study. Anat Embryol 1984;169: $151-8$

21 Torihashi S, Ward SM, Sanders KM. Development of c-Kit positive cells and the onset of electrical rhythmicity in murine small intestine. Gastroenterology 1997;112:144-55.

22 Ward SM, Harney SH, Bayguinov JR, et al. Development of electrical rhythmicity in the murine gastrointestinal tract is specifically encoded in the tunica muscularis. F Physiol 1997;505:241-58.

23 Smith TK, Reed JB, Sanders KM. Electrical pacemakers of canine proximal colon are functionally innervated by inhibicanine proximal colon are functionally innervated by inh

24 Berezin I, Huizinga JD, Farraway L, et al. Innervation of interstitial cells of Cajal by vasoactive intestinal polypeptide containing nerves in canine colon. Can f Physiol Pharmacol 1990;68:922-32.

25 Huizinga JD, Berezin I, Daniel EE, et al. Inhibitory innervation of colonic smooth muscle cells and interstitial cells of Cajal. Can $\mathcal{F}$ Physiol Pharmacol 1990;68:447-54.
26 Publicover NG, Horowitz NN, Sanders KM. Calcium oscillations in freshly dispersed and cultured interstitial cells from canine colon. Am F Physiol 1992;262:C589-97.

27 Publicover NG, Hammond EM, Sanders KM. Amplification of nitric oxide signaling by interstitial cells isolated from canine colon. Proc Natl Acad Sci USA 1993;190: 2087-91.

28 de Vente J, Schipper J, Steinbusch HW. Formaldehyde fixation of cGMP in distinct cellular pools and their recognition by different cGMP-antisera. An immunocytochemical study into the problem of serum specificity. Histochemistry 1989;91:401-12.

29 Burns AJ, Herbert T, Ward SM, et al. Interstitial cells of Cajal in the guinea-pig gastrointestinal tract as revealed by c-kit immunohistochemistry. Cell Tissue Res 1997;290:1120.

30 Wang X-Y, Sanders KM, Ward SM. Intimate relationship between interstitial cells of Cajal and enteric nerves in the guinea-pig small intestine. Cell Tissue Res 1999;295:24756.

31 Burnstock G. Neurotransmitters and trophic factors in the autonomic nervous system. F Physiol 1981;313:1-35.

32 Daniel EE, Posey-Daniel V. Neuromuscular structures in opossum esophagus: role of interstitial cells of Cajal. Am $\mathcal{F}$ Physiol 1984;246:G305-15. 